\title{
Publisher's Note: Peer Instruction in introductory physics: A method to bring about positive changes in students' attitudes and beliefs [Phys. Rev. Phys. Educ. Res. 13, 010104 (2017)]
}

Ping Zhang, Lin Ding, and Eric Mazur

(Received 19 January 2017; published 3 February 2017)

DOI: 10.1103/PhysRevPhysEducRes.13.019904

This paper was published online on 17 January 2017 with an incorrect volume number in the article identifier. The correct volume is "13." The paper has been corrected as of 19 January 2017.

Published by the American Physical Society under the terms of the Creative Commons Attribution 4.0 International license. Further distribution of this work must maintain attribution to the author(s) and the published articles title, journal citation, and DOI. 